\title{
Effect of using Photobiomodulation, stabilization, and anterior repositioning splints on the pain level of subjects with temporomandibular joint disc displacement with reduction
}

Efeito do uso da terapia a laser de baixa potência, placas planas e placas reposicionadoras anterior, no nível de dor de indivíduos com deslocamento anterior do disco articular com redução

Esmail Ahmed ABDEL-GAWWAD ${ }^{1}$, Abdel Aziz Baiomy ABDULLAH ${ }^{2}$, Mostafa Yassin FARHAT ${ }^{1}$, Mohamed Ahmed HELAL ${ }^{1}$ (])

1 - Al-Azhar University (Boys Branch), Faculty of Dentistry, Department of Removable Prosthodontics, Cairo, Egypt.

2 - Al-Azhar University (Assiut Branch), Faculty of Dentistry, Department of Oral and Maxillofacial Surgery, Assiut, Egypt.

\begin{abstract}
Objective: was to evaluate the effect of four conservative treatment modalities on the pain level of patients with temporomandibular joint (TMJ) anterior disc displacement with reduction (ADDwR). Material and methods: 100 subjects (64 females and 36 males) were selected, divided into four groups, 25 patients of each. Subjects of Group I have been treated with behavioral therapy. Subjects of Group II had been treated with Photobiomodulation therapy (PBMT). Subjects of Group III had been treated by anterior repositioning splint (ARS). Subjects of Group IV had been treated by a stabilization splint. The pain was evaluated by visual analog score (VAS) from 0 to 10. Statistical analysis was done using one-way ANOVA test for comparison between groups. Within each group, a comparison between baseline and after treatment was done using paired t-test $(\mathrm{p}<0.05)$. Results: There was a statistical difference between the pain scores of the different groups after treatment $(p \leq 0.05)$. Also, there were statistical differences between all groups $(p \leq 0.05)$ except that between group II and group III ( $>0.05)$. Conclusion: The use of stabilization splint and ARS are effective non-invasive methods for reducing the pain level in the treatment of TMJ ADDwR cases.
\end{abstract}

\section{KEYWORDS}

Anterior repositioning splint; Disc derangement; Disc displacement; Low level laser therapy; Photobiomodulation therapy; Stabilization splint; TMD.

\section{RESUMO}

Objetivo: avaliar o efeito de quatro modalidades de tratamento conservador no nível de dor de pacientes com deslocamento anterior do disco articular com redução. Material e Métodos: foram selecionados 100 indivíduos(64 mulheres e 36 homens), divididos em quatro grupos, 25 pacientes cada. Os indivíduos do Grupo I foram tratados com terapia comportamental. Os indivíduos do Grupo II foram tratados com terapia de fotobiomodulação. Os indivíduos do Grupo III foram tratados com placa de reposicionamento anterior. Os indivíduos do Grupo IV foram tratados com uma placa de estabilização. A dor foi avaliada pelo escala visual analógica (EVA) de 0 a 10. A análise estatística foi feita usando o teste ANOVA de uma via para comparação entre os grupos. Dentro de cada grupo, uma comparação entre a linha de base e após o tratamento foi feita usando o teste t pareado $(\mathrm{p}<0,05)$. Resultados: Houve diferença estatística entre os escores de dor dos diferentes grupos após o tratamento $(\mathrm{p} \leq 0,05)$. Além disso, houve diferenças estatísticas entre todos os grupos ( $\leq 0,05)$, exceto entre o grupo II e o grupo III $(\mathrm{p}>0,05)$. Conclusão: O uso de placa de estabilização e reposicionadora anterior são métodos não invasivos eficazes para reduzir o nível de dor no tratamento de casos de deslocamento anterior de disco articular sem redução.

\section{PALAVRAS-CHAVE}

Placa de reposicionamento anterior; Desarranjo de disco; Deslocamento de disco; Terapia a laser de baixa potência; Terapia de fotobiomodulação; Placa de estabilização; DTM. 


\section{INTRODUCTION}

TMJ is one of the most complex synovial joints in the human body both morphologically and functionally. Articular surfaces which form this joint are in contact with the articular disc, a nonvascular structure and nourished by synovial fluid, a secretion of the internal layer of the articular capsule, the synovial membrane. The articular disc appears in the sagittal view, as a biconcave structure that is positioned usually between the posterior slope of the articular eminence and the anterior medial surface of the mandibular condyle. It transversally splits the TMJ into two compartments, which are completely separate in normal conditions. Three different regions can be identified in the articular disc; the posterior band (the thickest portion), the intermediate band (the thinnest part), and the anterior band (with intermediate thickness) [1,2].

Disturbance in the normal anatomical disc-condyle relationship results in internal derangements of the TMJ [3]. Internal joint derangement is an orthopedic term defined as a localized mechanical fault interfering with smooth joint movement [4]. Structural surface irregularities, ankylosing conditions (adherence, adhesion, ankylosis), disc-condyle derangements (subluxation, luxation), loose bodies, and disc derangements (disc displacement, disc perforation) [5] are types of internal derangement of the TMJ. Disc displacement is the most common [6,7] and the most frequent subtype is anterior and/or medial displacement [8]. Lateral displacements also occur [7]. A few cases of posterior displacement have also been reported [9]. A displaced disc alters the normal function of the TMJ [10]. ADDwR can produce clicking during opening as well as closing of the mouth (reciprocal click) [11]. Joint clicking, joint pain, and masticatory muscle pain are common in the adolescent population [12].

The literature about the management of ADDwR is vast and confusing with various treatment protocols and divergent opinions. One of the reasons for the controversy is attributed to the fact that all the treatment approaches claim success and the most of patients are reported to improve [13]. This makes the rationale behind the selection of different treatment options constitute one of the most controversial areas in the field of TMD [14].
There are three basic treatment goals for patients with TMD or ADDwR: reducing pain, restoring function, and optimizing patients' quality of life [15]. In the literature, however, the treatment approaches used to achieve these goals are highly variable in invasiveness ranging from non-invasive reversible interventions to minimally-invasive and invasive irreversible interventions. Conservative therapy should be the first treatment choice to prevent the risk of postoperative surgical complications although there were instances where surgical interventions may be successful. Amongst conservative treatments are: behavioral therapy, hot and cold therapy, ARS, stabilizing splint, Photobiomodulation (Low Level Laser Therapy) [16-18].

Behavioral therapy is a psychologically-based treatment that has been proposed for patients suffering from chronic TMD pain [19], it can be considered as a safe, reversible, and conservative therapy that includes a broad range of interventions as biofeedback, cognitive behavioral therapy, patient re-education method, and relaxation technique which aim to reduce pain, pain-related disability and to increase pain coping skills by enhancing adaptive cognitions and behaviors [20-22].

Many types of occlusal splints can be used for occlusal equilibration, prevent the wearing of the natural teeth, or treatment of TMJ disorders [23], till now still there is considerable debate about the design of occlusal splints, how they should be used, and the mechanism of action. Various types of splints were investigated for the treatment of ADDwR, however, stabilization splint and ARS are the most commonly used types [24].

PBMT has been introduced recently as a non-invasive physical method for the treatment of TMD and myofascial pain [25]. PBMT is a form of phototherapy with its bio-stimulation and analgesic effects without thermal changes [26]. It is a successful, easily applicable, and short-term treatment option and has become widely used as an alternative treatment for TMD due to its analgesic, anti-inflammatory, and regenerative effects [27]. In the literature, there are many conservative treatments for ADDwR cases, however, little data are available regarding which one of them having the ability to decrease the pain for ADDwR cases more than the others. Therefore, this study was aimed to study the 
effect of four conservative treatment modalities (Behavioral therapy, Photobiomodulation therapy, anterior repositioning splint, and stabilization splint) on the pain level of ADDwR cases. The null hypothesis of this study was that the difference between the effect of different treatment modalities (Behavioral therapy, PBMT, ARS, and stabilization splint) on reducing the pain for ADDwR cases would be insignificant.

\section{SUBJECTS AND METHODS}

Patients attending the Department of Removable Prosthodontics clinic, Faculty of Dental Medicine, Al-Azhar University, were recruited over a period of 4 years (March 2016 - April 2020). A total of 100 subjects were selected (64 females and 36 males), their ages were ranging from 21 to 44 years old. All subjects were diagnosed with TMJ ADDwR according to research diagnostic criteria for temporomandibular disorders (RDC/TMD) [28], also they were examined before treatment using magnetic resonance imaging (Ingenia S, MRI system, Philips, Amsterdam, Netherlands) of TMJ bilaterally to evaluate the joint effusion, integrity of articular disc and its form and location during neutral position.

The inclusion criteria were; subjects diagnosed with unilateral internal derangement of TMJ, subjects with a chief complaint of TMJ pain, noise, and limited maximum mouth opening, subjects with consistent reciprocal joint clicking sounds at both early/late opening and late closing, previous history of limited mouth opening for more than two weeks and pain in the TMJ area aggravated by jaw movement and function.

The exclusion criteria were; patients with a history of previous TMJ surgery, history of head and neck radiotherapy or chemotherapy, patients with systemic inflammatory joint disease or with a pathological lesion in the joint, patients with direct trauma to the facial bones, patients with congenital disturbances as hyperplasia or hypoplasia of the joint, patients with osteoarthritic changes in the TMJ bony components and patients with loss of the normal TMJ disc architecture (over thinning or perforations). Diagnosis and treatment evaluations were made by two examiners experienced in TMD diagnosis. They were always blinded to the participant's interventions and grouping.

Ethical approval had been obtained from the institutional ethical review committee, also written consent form had been signed by each subject before conducting any procedures.

All treatments were performed by two skilled professionals who performed the randomization process. Randomization was made by IBM SPSS software and block random allocation was employed. Subjects were randomly categorized into four groups, 25 subjects of each ( 9 males and 16 females). Group I: Subjects were treated by using behavioral therapy. Group II: Subjects were treated by using PBMT. Group III: Subjects were treated ARS. Group IV: Subjects were treated with stabilization splints. A flowchart of patients participation and the study profile is shown in Figure 1

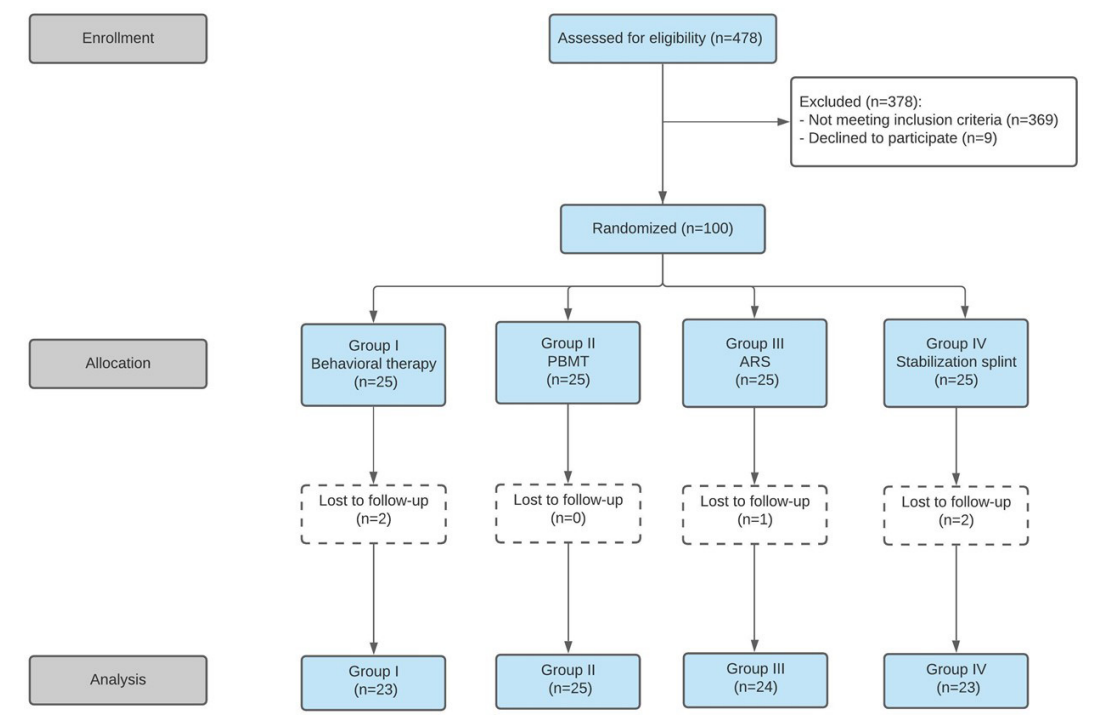

Figure 1 - Flow chart of patients participation and the study profile. 
Group I: A booklet having all instructions and information was given to each subject; each one was advised to rest the TMJ as much as possible, to avoid hard and tough food, to use thermal packs, and to avoid forehead position and wrong working/sleeping positions. The patients were instructed to maintain the recommendations for 6 months.

Group II: Subjects were treated with PBMT two times a week during the four weeks of the treatment period (total of 8 sessions) using Tower light laser (Elettronica Pagani, Paderno Dugnano, Milan, Italy). Each session involved laser application in five predetermined TMJ points (anterior, superior, posterior, posteroinferior points of the condylar position, and in the external auditory meatus). Emitted radiation was obtained from a solid-state laser source with a wavelength of $808 \mathrm{~nm}$. Output power of $70 \mathrm{~mW}$, doses of $105 \mathrm{~J} / \mathrm{cm}^{2}$ (energy density), and exposure time of 60 seconds were adjusted and PBMT was applied preciously on the predetermined points. (the dosage is calculated as power $(\mathrm{W}) /$ beam area $\left(\mathrm{cm}^{2}\right) \times$ time $\left.(\mathrm{s})=\mathrm{J} / \mathrm{cm}^{2}\right)$

Group III: Maxillary ARS was constructed for each subject to keep the mandible in the anterior position using a $2 \mathrm{~mm}$ polyethylene terephthalate sheet (Folidur N/ clear, Thermoforming Sheet, aldente Dentalprodukte GmbH, Horgenzell, Germany) and auto curing acrylic resin (Vertex Orthoplast, Zeist, Netherland) (Figure 2). Subjects were requested to wear the splints at least 12 hours/day for 6 months, also no medication was prescribed to them.

Group IV: Maxillary stabilization splint was constructed for each subject using polyethylene terephthalate sheet and self-curing acrylic resin (Figure 3). The stabilization splint was adjusted to fulfill the following requirements: during protrusive movement, mandibular canines must contact the appliance, in any lateral movement only the mandibular canine should exhibit laterotrusive contact on the appliance, and mandibular posterior teeth must contact the appliance only in centric relation closure. Instructions were then given to the patient about the use and care of the appliance. Also, each subject was requested to wear the splints at least 12 hours/day for 6 months, also no medication was prescribed to the subjects.

Standard pain scoring was carried out before treatment and after six months through a visual

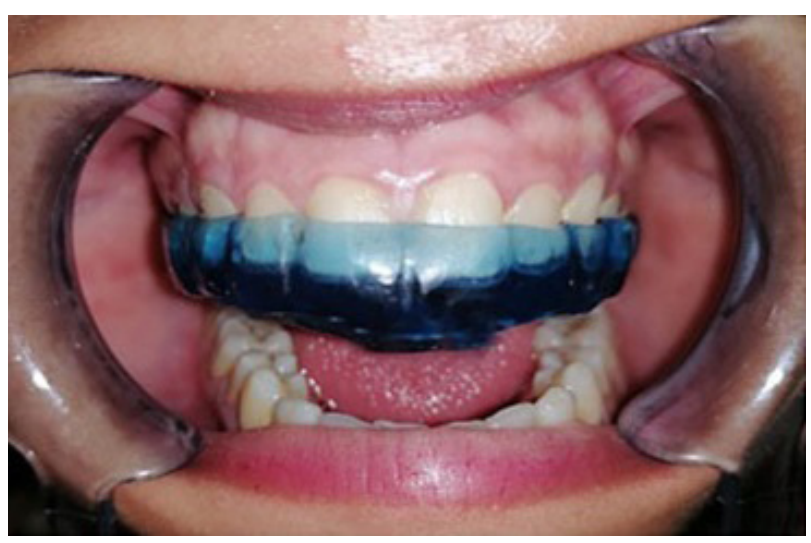

Figure 2 - Anterior repositioning splint.

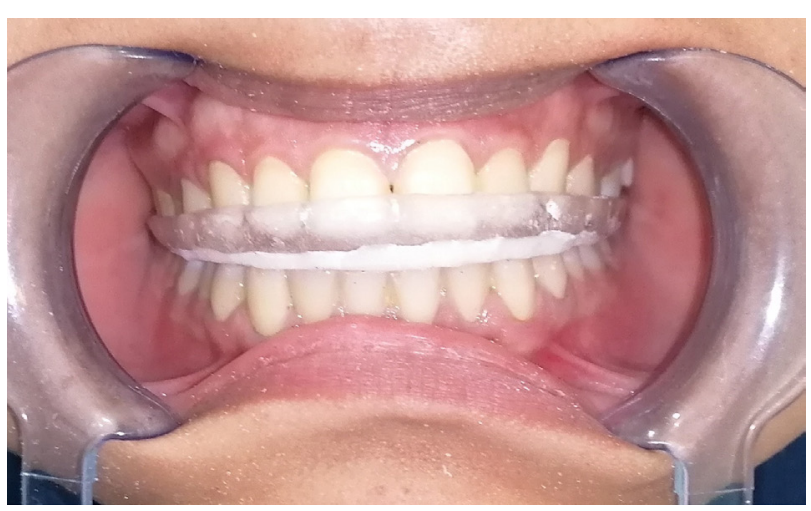

Figure 3 - Stabilization splint

analog scale (VAS) with endpoints 0 score for no pain and 10 score for the worst pain experienced.

Statistical analysis: Data were collected, tabulated, and statistically analyzed by using paired t-test and one-way ANOVA test followed by post hoc Tukey test at 95\% confidence level $(\mathrm{p} \leq 0.05)$.

\section{RESULTS}

The mean values of pain scores of different groups at $1^{\text {st }}$ session and after 6 months are shown in Table I. After 6 months of treatment, the highest score was in group I, and the lowest score was in group IV.

Paired t-test showed a significant difference between the pain scores at $1^{\text {st }}$ session and after 6 months of the ADDwR cases for each group at 95\% confidence level $(p \leq 0.05)$ except that for group I ( $\mathrm{p}>0.05)$.

Table II shows a comparison between different groups with one-way ANOVA and the pairwise comparisons between groups using post hoc Tukey test. one-way ANOVA test showed no 
Table I - Mean and SD values for Pain score with paired t-test for different time comparison $(p<0.05)$

\begin{tabular}{|c|c|c|c|c|c|}
\hline & & Group I & Group II & Group III & Group IV \\
\hline \multicolumn{2}{|c|}{ No. of subjects } & 23 & 25 & 24 & 23 \\
\hline \multicolumn{2}{|c|}{ Baseline } & $6.9 \pm 1.37$ & $6.4 \pm 1.7$ & $6.7 \pm 1.3$ & $6.1 \pm 1.4$ \\
\hline \multicolumn{2}{|c|}{6 months } & $6.5 \pm 1.63$ & $4.4 \pm 1.62$ & $2.6 \pm 1.02$ & $0.8 \pm 0.63$ \\
\hline \multirow{2}{*}{ Paired t-test } & $\mathrm{T}$ value & 2.262 & 2.262 & 2.262 & 2.262 \\
\hline & $P$ value & 0.55 & 0.022 & 0.0001 & 0.0009 \\
\hline
\end{tabular}

Table II - Pairwise comparison using post hoc Tukey test for between different groups $(p \leq 0.05)$.

\begin{tabular}{|cccc} 
& & $\begin{array}{c}\text { Mean } \\
\text { Difference }\end{array}$ & P-value \\
\hline \multirow{2}{*}{ Group I Vs } & Group II & $3.900^{*}$ & .000 \\
& Group III & $2.200^{*}$ & .008 \\
\hline \multirow{2}{*}{ Group II Vs } & Group IV & $5.700^{*}$ & .000 \\
\hline \multirow{2}{*}{ Group III Vs } & Group IV & $1.800^{*}$ & .039 \\
\hline
\end{tabular}

* significant difference

statistical difference between the pain scores of the different groups at the baseline $(\mathrm{p}>0.05)$, while there was a statistical difference between the pain scores of the different groups after treatment at 95\% confidence level $(p \leq 0.05)$. Post hoc Tukey test showed statistically significant differences between all groups at 95\% confidence level ( $p \leq 0.05)$ except that between group II and group III ( $\mathrm{p}>0.05)$. Serious complications or side effects such as severe alteration of occlusion, teeth intrusion, or mobility haven't been observed in any participant of the four treatment groups.

\section{DISCUSSION}

ADDwR is one of the most common TMJ disorders and occurs in patients of all ages, although it has a high prevalence in young adults $[29,30]$. Disc displacement prevalence in adults varies between $75 \%$ and $94 \%$ in clinically symptomatic patients, recruited from a population seeking TMD treatment [31].

Epidemiological studies revealed that female patients of reproductive age are mostly affected with TMD and seek more treatment than the males [32], which was confirmed in the sample of the current study.

This study was done on 100 subjects, according to the line of treatment the selected subjects were distributed on four groups,
25 subjects of each (9 males and 16 females), also five subjects rejected to complete this study and decided to withdraw due to personal reasons (unavailability or moving to another place).

ADDwR treatments may be conservative (or non-invasive) or non-conservative (or invasive). Amongst conservative treatments are: behavioral therapy, ARS, stabilizing splints, and PBMT [16-18].

The pathogenic pathways of ADDwR are not clearly known, thus conservative methods are usually preferred as the first-line treatment modality. If conservative treatment is inadequate, surgical treatment is needed [33]. The aim of the treatment in TMD subjects is to eliminate or reduction of the TMJ pain and provide normal TMJ function [33].

In previous studies designed for evaluation of the effectiveness of splint therapies, untreated control groups were used $[34,35]$ but not in some others [36]. In these studies, the subjects included in the so-called "control group" or "natural course", cannot be evaluated as untreated. When subjects are observed periodically, the inert untreated group turns into an active treatment group because of the changes in the patient's cognitive expectancy, thus this study included a behavioral therapy group instead of a control group or natural course group.

Thermotherapy (hot fomentation) was added to the behavioral therapy group as it's recommended by the American Academy of Orofacial Pain to relieve pain and dysfunction associated with TMD, improve muscle tone, and relax mandibular muscles [37].

In this study, four conservative treatment approaches were evaluated and it was sought to determine the benefits and superiority of each technique. Subjects with ADDwR were divided randomly into four treatment groups: behavioral therapy, PBMT, ARS, and stabilization splint. The results were evaluated at the $1^{\text {st }}$ session and after six months, and the clinical outcome as pain 
score was assessed for each subject of each group. It was difficult to make the active treatment periods similar among the four treatment groups due to the difference in treatment modalities and treatment protocol as each line of treatment has its own therapeutic period, however, the evaluation time was the same for all groups (after six months from the baseline session) and this was in agreement with previous studies [38-43]

There was a significant effect for PBMT, ARS, and stabilization splint in the reduction of pain scores of ADDwR cases $(p \leq 0.05)$, however, there was an insignificant effect for the behavioral therapy in reduction of pain scores in ADDwR cases ( $\mathrm{p}>0.05)$.

The previous results revealed that there was a significant difference between the pain scores of the different groups after treatment $(p \leq 0.05)$. Therefore, the null hypothesis, denoting that there are no differences between the effectiveness of the different treatment modalities (Behavioral therapy, PBMT, ARS, and stabilization splint) on reducing the pain of ADDwR cases was rejected.

In the present study, TMJ pain was significantly reduced after treatment with both stabilization splint and anterior repositioning splint; this was in agreement with Lundh et al. [34], who credited it to the healing of discal elongation. The reduction of the pain level of ADDwR cases may be due to the decrease in TMJ loading, which was related to the considerable increase in the posterosuperior space [44].

The stabilization group displayed greater significant improvement in pain level more than the ARS group however Stiesch-Scholz et al. [45] reported that the stabilization splint and ARS having a similar significant improvement effect for ADDwR cases.

In recent years, PBMT has also been preferred for the treatment of painful TMD, and successful clinical trials have been reported as reported by several studies [46-48]. However, other studies $[49,50]$ have reported no significant difference between PBMT and placebo with regard to the treatment outcomes of TMD which may be attributed to variation in laser type, dosages, wavelength, treatment time, and sessions. In the present study, the PBMT group showed a less reduction in pain score compared to both splint groups, which was in agreement with a previous study by Demirkol et al. [41].
The behavioral therapy group showed a statistically non-significant difference in pain score before and after treatment that was in accord with a previous study by Okeson et al. [51] who compare occlusal splint with relaxation therapy and concluded that relaxation therapy is not effective in reducing the symptom associated with TMD.

The limitation of this study is that pain perception is subjective and the pain score depends on the patient's personal responses; in addition, the pain threshold is variable as well. Another limitation of this study is the short follow-up period which was not sufficient to completely address the controversy about different conservative treatment modalities of TMD. So further studies are needed to evaluate the long-term efficacy of these treatments, also this study recommends using PBMT as an adjunctive treatment to occlusal splint to relieve pain associated with TMD.

\section{CONCLUSIONS}

- Using the stabilization splint and ARS are effective treatment methods in reducing the pain level in subjects with ADDwR, and the best results were achieved with stabilization splint.

Behavioral therapy mustn't be used alone for the treatment of chronic TMD pain. It's advisable to use Photobiomodulation therapy as an adjunctive treatment to occlusal splint to relieve pain associated with TMD.

\section{Acknowledgments}

None

\section{Conflict of Interest}

The authors have no conflict of interest related for this study.

\section{Funding}

This study was self-funded

\section{Regulatory Statement}

This study was conducted in accordance with all the provisions of the local human subject's oversight committee guidelines and policies of the 


\section{Faculty of Dental Medicine, Al-Azhar University, Cairo, Egypt}

\section{REFERENCES}

1. Ramos ACA, Sarmento VA, Campos PSF, Gonzalez MOD. Articulação temporomandibular - aspectos normais e deslocamentos de disco: imagem por ressonância magnética. Radiol Bras. 2004;37(6):449-54. http://dx.doi.org/10.1590/ S0100-39842004000600013.

2. Hylander W. Functional anatomy and biomechanics of the masticatory apparatus. In: Laskin DM, Greene CS, Hylander WL, editors Temporomandibular disorders temporomandibular disorders: an evidenced approach to diagnosis and treatment. USA: Quintessence Publishing; 2006

3. Laskin D. Etiology and pathogenesis of internal derangement of the temporomandibular joint. Oral Maxillofac Surg Clin North Am. 1994;6:217-22

4. Hamblen DL, Simpson AHRW, Raby N. Adams's outline of orthopaedics. London: Churchill Livingstone; 2010

5. Stegenga B. Osteoarthritis of the temporomandibular joint organ and its relationship to disc displacement. J Orofac Pain. 2001;15(3):193-205. PMid:11575190.

6. Dolwick MF, Katzberg RW, Helms CA, Bales DJ. Arthrotomographic evaluation of the temporomandibular joint. J Oral Surg. 1979:37(11):793-9. PMid:290770.

7. Katzberg RW, Dolwick MF, Helms CA, Hopens T, Bales DJ, Coggs GC. Arthrotomography of the temporomandibular joint. AJR Am J Roentgenol. 1980;134(5):995-1003. http://dx.doi.org/10.2214/ ajr.134.5.995. PMid:6768279.

8. Westesson P-L. Double-contrast arthrotomography of the temporomandibular joint: introduction of an arthrographic technique for visualization of the disc and articular surfaces. J Oral Maxillofac Surg. 1983;41(3):163-72. http://dx.doi. org/10.1016/0278-2391(83)90074-5. PMid:6572227.

9. Bronstein S, Tomasetti B, Ryan D. Internal derangements of the temporomandibular joint: correlation of arthrography with surgical findings. J Oral Surg. 1981;39(8):572-84.

10. Okeson JP. Occlusal appliance therapy: management of temporomandibular disorders and occlusion. 5th ed. St. Louis: Mosby; 2003. p. 220-442

11. Dworkin SF, LeResche L. Research diagnostic criteria for temporomandibular disorders: review, criteria, examinations and specifications, critique. J Craniomandib Disord. 1992;6(4):301-55

12. Mintz SS. Craniomandibular dysfunction in children and adolescents: a review. Cranio. 1993;11(3):224-31. http://dx.doi. org/10.1080/08869634.1993.11677970. PMid:8242787.

13. Okeson JP. Orofacial pain: guidelines for assessment, diagnosis, and management. USA: Quintessence Publishing Co Inc.; 1996.

14. Forssell H, Kalso E. Application of principles of evidence-based medicine to occlusal treatment for temporomandibular disorders: are there lessons to be learned? J Orofac Pain. 2004;18(1):9-22, discussion 23-32. PMid:15022533.

15. de Leeuw R, Klasser GD. Diagnosis and Management of TMDs, In: de Leeuw R, Klasser GD, editors. Orofacial Pain: Guidelines for Assessment, Diagnosis, and Management. USA: Quintessence Publishing Co, Inc; 2013. p. 127-86.

16. Fricton JR. Temporomandibular muscle and joint disorders. IASPPain. Clin Update. 2004;12(2):1-6.

17. Shedden Mora MC, Weber D, Neff A, Rief W. Biofeedback-based cognitive-behavioral treatment compared with occlusal splint for temporomandibular disorder: a randomized controlled trial.
Clin J Pain. 2013;29(12):1057-65. http://dx.doi.org/10.1097/ AJP.0b013e3182850559. PMid:23446073.

18. Herpich CM, Leal-Junior ECP, Politti F, de Paula Gomes CAF, Dos Santos Glória IP, de Souza Amaral MFR, et al. Intraoral photobiomodulation diminishes pain and improves functioning in women with temporomandibular disorder: a randomized, sham-controlled, double-blind clinical trial: Intraoral photobiomodulation diminishes pain in women with temporomandibular disorder. Lasers Med Sci. 2020;35(2):439-45. http://dx.doi.org/10.1007/s10103-019-02841-1. PMid:31325122.

19. Rollman GB, Gillespie JM. The role of psychosocial factors in temporomandibular disorders. Curr Rev Pain. 2000;4(1):71-81. http://dx.doi.org/10.1007/s11916-000-0012-8. PMid:10998718.

20. Sherman JJ, Turk DC. Nonpharmacologic approaches to the management of myofascial temporomandibular disorders. Curr Pain Headache Rep. 2001;5(5):421-31. http://dx.doi. org/10.1007/s11916-001-0053-7. PMid:11560807.

21. Turner JA, Mancl L, Aaron LA. Short- and long-term efficacy of brief cognitive-behavioral therapy for patients with chronic temporomandibular disorder pain: a randomized, controlled trial. Pain. 2006;121(3):181-94. http://dx.doi.org/10.1016/j. pain.2005.11.017. PMid:16495014.

22. Calderon PS, Tabaquim ML, Oliveira LC, Camargo AP, Ramos TC No, Conti PC. Effectiveness of cognitive-behavioral therapy and amitriptyline in patients with chronic temporomandibular disorders: a pilot study. Braz Dent J. 2011;22(5):415-21. http://dx.doi.org/10.1590/S0103-64402011000500012. PMid:22011899.

23. Deshpande RG, Mhatre S. TMJ disorders and occlusal splint therapy-a review. Int J Dent Clin. 2010;2(2):22-9.

24. Santacatterina A, Paoli M, Peretta R, Bambace A, Beltrame A. A comparison between horizontal splint and repositioning splint in the treatment of 'disc dislocation with reduction'. Literature meta-analysis. J Oral Rehabil. 1998;25(2):81-8. http://dx.doi. org/10.1046/j.1365-2842.1998.00219.x. PMid:9576589.

25. Mazzetto MO, Hotta TH, Pizzo RC. Measurements of jaw movements and TMJ pain intensity in patients treated with GaAlAs laser. Braz Dent J. 2010;21(4):356-60. http://dx.doi. org/10.1590/S0103-64402010000400012. PMid:20976388.

26. Öz S, Gökçen-Röhlig B, Saruhanoglu A, Tuncer EB. Management of myofascial pain: low-level laser therapy versus occlusal splints. J Craniofac Surg. 2010;21(6):1722-8. http://dx.doi.org/10.1097/ SCS.0b013e3181f3c76c. PMid:21119408

27. Herranz-Aparicio J, Vázquez-Delgado E, Arnabat-Domínquez J España-Tost A, Gay-Escoda C. The use of low level laser therapy in the treatment of temporomandibular joint disorders. Review of the literature. Med Oral Patol Oral Cir Bucal. 2013;18(4):e603-12. http://dx.doi.org/10.4317/medoral.18794. PMid:23722130.

28. Schiffman E, Ohrbach R, Truelove E, Look J, Anderson G, Goulet $J$-P, et al. Diagnostic criteria for temporomandibular disorders (DC) TMD) for clinical and research applications: recommendations of the International RDC/TMD Consortium Network and Orofacial Pain Special Interest Group. J Oral Facial Pain Headache. 2014;28(1):6-27. http://dx.doi.org/10.11607/jop.1151. PMid:24482784.

29. Hu YK, Yang C, Xie QY. Changes in disc status in the reducing and nonreducing anterior disc displacement of temporomandibular joint: a longitudinal retrospective study. Sci Rep. 2016;6(1):34253. http://dx.doi.org/10.1038/srep34253. PMid:27671371.

30. Ikeda K, Kawamura A, Ikeda R. Prevalence of disc displacement of various severities among young preorthodontic population: a magnetic resonance imaging study. J Prosthodont. 2014;23(5):397-401. https://doi.org/10.1111/jopr.12126.

31. Manfredini D, Guarda-Nardini L. Agreement between Research Diagnostic Criteria for Temporomandibular Disorders and magnetic resonance diagnoses of temporomandibular disc displacement in 
a patient population. Int J Oral Maxillofac Surg. 2008;37(7):612-6 http://dx.doi.org/10.1016/j.ijom.2008.04.003. PMid:18486451.

32. Wang J, Chao Y, Wan Q, Zhu Z. The possible role of estrogen in the incidence of temporomandibular disorders. Med Hypotheses. 2008;71(4):564-7. http://dx.doi.org/10.1016/j.mehy.2008.05.011. PMid:18597950.

33. Suvinen TI, Reade PC, Hanes KR, Könönen M, Kemppainen P. Temporomandibular disorder subtypes according to selfreported physical and psychosocial variables in female patients: a re-evaluation. J Oral Rehabil. 2005;32(3):166-73. http://dx.doi org/10.1111/j.1365-2842.2004.01432.x. PMid:15707426

34. Lundh H, Westesson PL, Kopp S, Tillström B. Anterior repositioning splint in the treatment of temporomandibular joints with reciprocal clicking: comparison with a flat occlusal splint and an untreated control group. Oral Surg Oral Med Oral Pathol. 1985;60(2):131-6. http://dx.doi.org/10.1016/00304220(85)90280-4. PMid:3862019.

35. Tecco S, Festa F, Salini V, Epifania E, D'Attilio M. Treatment of joint pain and joint noises associated with a recent TMJ internal derangement: a comparison of an anterior repositioning splint, a full-arch maxillary stabilization splint, and an untreated control group. Cranio. 2004;22(3):209-19. http://dx.doi.org/10.1179/ crn.2004.026. PMid:15293777.

36. Conti PC, Miranda JE, Conti AC, Pegoraro LF, Araújo CR. Partial time use of anterior repositioning splints in the management of TMJ pain and dysfunction: a one-year controlled study. J Appl Oral Sci. 2005;13(4):345-50. https://doi.org/10.1590/s167877572005000400006

37. De Leeuw R, Klasser GD. Orofacial pain: guidelines for assessment, diagnosis, and management. 4th ed: Quintessence Chicago; 2008. 316 p

38. Helal MA, Agou SH, Bayoumi A, Imam A, Hassan AH Management of internal derangement of temporomandibular joint disc displacement with reduction using two different lines of treatment. Braz Dent Sci. 2021;24(2):8. http://dx.doi. org/10.14295/bds.2021.v24i2.2080.

39. Kurt A, Guner-Onur S, Bilmenoglu C, Memisoglu G, Cilingir AA. Efficacy of different treatment methods in patients with myofascial pain syndrome. Lasers in Dental Science. 2020;4(4):1816. http://dx.doi.org/10.1007/s41547-020-00103-w.

40. Hosgor H, Bas B, Celenk C. A comparison of the outcomes of four minimally invasive treatment methods for anterior disc displacement of the temporomandibular joint. Int J Oral Maxillofac Surg. 2017;46(11):1403-10. http://dx.doi. org/10.1016/j.ijom.2017.05.010. PMid:28602569.
41. Demirkol N, Sari F, Bulbul M, Demirkol M, Simsek I, Usumez A Effectiveness of occlusal splints and low-level laser therapy on myofascial pain. Lasers Med Sci. 2015;30(3):1007-12. http:// dx.doi.org/10.1007/s10103-014-1522-7. PMid:24504660.

42. Altindiș T, Güngörmüș M. Thermographic evaluation of occlusal splint and low level laser therapy in myofascial pain syndrome. Complement Ther Med. 2019;44:277-81. http://dx.doi. org/10.1016/j.ctim.2019.05.006. PMid:31126567.

43. Maracci LM, Stasiak G, de Oliveira Chami V, Franciscatto GJ, Milanesi J, Figueiró $C$, et al. Treatment of myofascial pain with a rapid laser therapy protocol compared to occlusal splint: a double-blind, randomized clinical trial. Cranio. 2020;1-7. http:// dx.doi.org/10.1080/08869634.2020.1773661. PMid:32491964.

44. Bashir U, Naidu TNRR, Sangur R, Lakshmanarao. Vitality of occlusal splint therapy. Int J Appl Dent Sci. 2016;2(1):28-31.

45. Stiesch-Scholz M, Kempert J, Wolter S, Tschernitschek H, Rossbach AJDZZ. A comparison of a stabilisation splint and a pivot splint therapy in patients with anterior disk displacement. Dtsch Zahnarztl Z. 2004;59(8):439-43

46. Carrasco TG, Mazzetto MO, Mazzetto RG, Mestriner W Jr. Low intensity laser therapy in temporomandibular disorder: a phase II double-blind study. Cranio. 2008;26(4):274-81. http://dx.doi. org/10.1179/crn.2008.037. PMid:19004308.

47. Cetiner S, Kahraman SA, Yücetas S. Evaluation of low-leve laser therapy in the treatment of temporomandibular disorders. Photomed Laser Surg. 2006;24(5):637-41. http://dx.doi. org/10.1089/pho.2006.24.637. PMid:17069496

48. Fikácková H, Dostálová T, Navrátil L, Klaschka J. Effectiveness of low-level laser therapy in temporomandibular joint disorders: a placebo-controlled study. Photomed Laser Surg. 2007;25(4):297303. http://dx.doi.org/10.1089/pho.2007.2053. PMid:17803388.

49. Venancio RA, Camparis CM, Lizarelli RF. Low intensity laser therapy in the treatment of temporomandibular disorders: a double-blind study. J Oral Rehabil. 2005;32(11):800-7. http:// dx.doi.org/10.1111/j.1365-2842.2005.01516.x. PMid:16202043

50. Hansen HJ, Thorøe U. Low power laser biostimulation of chronic oro-facial pain. A double-blind placebo controlled cross-over study in 40 patients. Pain. 1990;43(2):169-79. http://dx.doi. org/10.1016/0304-3959(90)91070-Y. PMid:1708118.

51. Okeson JP, Moody PM, Kemper JT, Haley JV. Evaluation of occlusal splint therapy and relaxation procedures in patients with temporomandibular disorders. J Am Dent Assoc. 1983;107(3):420-4. http://dx.doi.org/10.14219/jada. archive.1983.0275. PMid:6355230

\section{Mohamed Ahmed Helal \\ (Corresponding address)}

Al-Azhar University, Faculty of Dentistry, Department of Removable Prosthodontics,

Nasr City, Cairo, Egypt.

Email: mhelal@azhar.edu.eg

Date submitted: 2020 December 07 Accepted submission: 2021 June 20 